\title{
Changing prevalence of respiratory symptoms and treatment $i$ Dutch school children: 1989-199
}

\author{
Konique Mommers, Ron Derkx, Gerard Swaen, Onno van Schayc
}

\author{
Abstrac \\ Aim: \\ ,To investigate whether the prevalence of respiratory symptoms \\ physicians visits, medication use and school absence in Dutc \\ ghildren changed between 1989 and 1997, and whether respirator \\ stymptoms are related to changed exposure to tobacco smoke an \\ pets \\ Methods: \\ Rarents of children eligible for a routine physical examination i \\ 1989 (3176 children), 1993 (3491 children) or 1997 (4776 children) \\ were asked to complete a questionnaire about respiratory symptom \\ for their child \\ Results: \\ Response rates were almost 100\%. Between 1989 and 1997 th \\ prevalence of shortness of breath increased from $7.4 \%$ to $9.3 \%$
}

$g=0.056)$ in 5-6 year olds, whereas the prevalence of wheezin decreased (from $22.1 \%$ to $18.3 \%, \mathrm{p}=0.002$ ). The same trend wa seen in 8-9 year-old children. The proportion of asthmatic childre nonsulting their physician or using medication increased (fro $55.9 \%$ to $63.3 \%$ and from $38.7 \%$ to $47.4 \%$, respectively), wherea ongarette smoking (from $60.8 \%$ to $48.5 \%$ ) and pet ownership (fro $55.1 \%$ to $47.0 \%$ ) decreased

\section{Conclusion}

Our findings support other reports of an increasing prevalence o ysthma and treatment. However, this could not be explained b increased exposure to cigarette smoke or pets

Key words

nespiratory symptoms, asthma, prevalence, childre

\section{Introductio}

Respiratory symptoms are a major health burden; fo Eutch school children it was reported that of th ghildren with asthmatic complaints $38 \%$ were usin medication and $22 \%$ had missed school for at least week in the past year ${ }^{1}$

\section{Monique Mommer \\ Epidemiologis}

\section{Ron Derk}

Head of Dept. Genera

Health Care, Westelijke

Mijnstree

Gerard Swae

Associate Professor o

Dccupationa

Epidemiolog

Bnno van Schayc

Professor of Genera

Eractic

\section{Correspondence to}

M. Mommer

Researchinstitute fo

Extramural an

Eransmural Health Car

University of Maastrich

B.O. Box 61

6200 MD Maastrich

The Netherland

4el: + (31) 43388231

monique.mommers@wanadoo.n

Prim Care Resp

2002;11( )138-4 marge geographic differences in asthma sympto prevalence have been reported, with the highes prevalence rates in Anglo-Saxon countries ${ }^{3}$, Also shortly after the reunification of East and Wes ,Germany, a higher prevalence of atopic sensibilisation asthma and hay fever was found in former Wes German children compared to East German children 4 Regional differences in asthma symptom prevalenc have also been reported for the Netherlands ${ }^{5}$ As i other countries ${ }^{8-}$ anrising asthma sympto prevalence has also been observed in the Netherland in recent years ${ }^{9}$, The causes of these geographica and temporal differences remain largely unexplained. The aim of the present study was to investigat ,whether the prevalence of respiratory symptoms physicians visits, medication use and schoo hbsenteeism due to respiratory complaints, in Dutc school children changed between 1989 and 1997. I sddition, we studied whether respiratory symptom vere associated with changed exposure to tobacc smoke and pets, in order to explain underlyin mechanisms of possible changes in asthma prevalence

Method

Study area and populatio

The Westelijke Mijnstreek is located in the souther part of the Netherlands (Limburg) and ha approximately 170,000 inhabitants.

The survey was performed among children that wer eligible for their routine physical examination by th
Youth Health Care Section of the Municipal Healt Service in 1989, 1993 or 1997. Figure 1 shows tha children were invited according to year of birth. Fo example, from October 1988 through March 1989 al 5-6 year-olds, born in 1983 were invited, followed b 8-9 year-olds born in 1980 (from April 1989 throug September 1989). Consequently, this approach ensure Enrolment of all 8-9 year-olds born in 1980 and 5dear-olds born in two consecutive years (i.e., 1983 an \$984) in the survey of 1989. In 1997 we extended th fecruitment through March 1998 to include all 5year-olds born in 1992 in the study (the study yea 1997-1998 will further be denoted as 1997)

\section{Questionnair}

th 1989,1993 and 1997 the same validate questionnaire was used 10,1 This questionnaire ha been used widely in the Netherlands and include questions on respiratory symptoms which wer slerived from internationally used standard children' questionnaires. Questions were asked about chroni eough (coughing five days a week for more than thre months a year), coughing with phlegm (coughing wit phlegm for more than three weeks a year), wheezing shortness of breath and shortness of breath wit wheezing. Additional questions were asked abou physicians visits, medication use, school absenteeis and indoor environment

\section{Đata analysi}

Eor each of the respiratory symptoms, the prevalenc was calculated by dividing the number of positiv fesponses to each question by the total number 0 fesponses to that question. To restrict the number o questions, respiratory symptoms were subdivided int asthmatic symptoms (one or more positive answers t the questions about recent wheezing, shortness o dreath and shortness of breath with wheezing) an soughing (a positive answer to one or both question sbout coughing). Questions on wheezing and shortnes 
Figure 1. Outline of the study. Grey and white areas represent the time periods in which 5-6 year olds (grey areas: October throug March) and 8-9 year-olds (white areas: April through September) respectively, were invited for a routine physical examination. Th year mentioned in grey and white areas represents the year of birth of the children

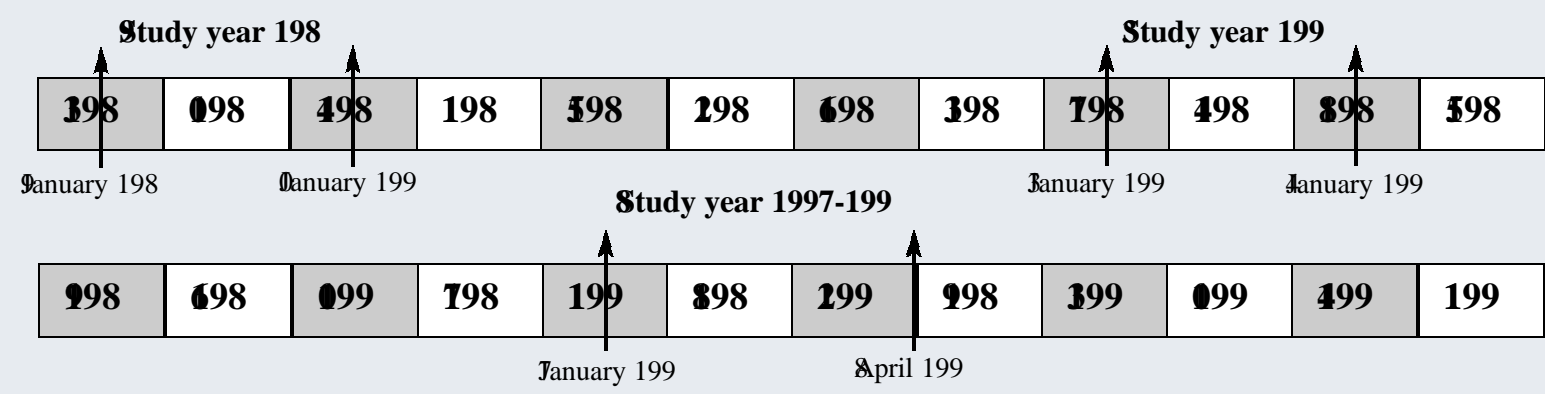

ef breath were previously found to be mor

discriminative when using the history by a doctor as a independent criterion than were questions asking abou coughing 1

Data are presented by age group and study year Mantel-Haenszels $\chi^{2}$ test for linear association wa used to test differences in prevalence rates between th three study years for linear association.

\section{Result}

By combining the survey with the physica examination routinely performed on school children bigh response rates were attained. In 1989 th questionnaire was completed for $3176(97.3 \%$ ahildren, in 1993 for 3491 (97.5\%) children and i \$997 for 4776 children. Due to a technical problem th jist of children invited in 1997 could not be completel æetrieved. Therefore, the response rate could only $b$ Ealculated for 2032 of the invited children; for 97.7 of these children the questionnaire was completed. I Æiew of the high response rates, selective non-respons is not likely. The boys to girls ratio was similar for the fhree study years (Table 1). In 1989 the proportion o 5-6 year-olds was somewhat lower within the 4-7 ag group as was the proportion 8-9 year-olds within the 8-12 age group, compared to 1993 and 1997

Wheezing was the most frequently reported complain $\mathrm{m}$ both age groups, followed by shortness of breat and shortness of breath with wheezing (Table 2) Chronic cough was the least prevalent respirator symptom

fn all three years of observation the prevalence o eespiratory symptoms was generally higher at the ag of 5-6 years than at the age of 8-9 years. In both ag groups, the prevalence of recent shortness of breat dnd recent shortness of breath with wheezing increase during the study period. Also, the prevalence o ohronic cough showed a small, statistically no fignificant increase. At the same time the prevalence o recent wheezing decreased; which reached statistica significance in the younger age group

The frequency of school absence decreased during th study period, although in 8-9 year-old children th decline was not seen until 1993. The prevalence o school absence due to respiratory symptoms wa nirtually the same in 1989 and 1997, but was higher i 11993. The proportion of children consulting thei physician or using medication for respirator domplaints remained unchanged between 1989 an 1997

In children who coughed as well as in asthmat dhildren, the prevalence of physicians visits an medication use increased from 1989 to 1997 (Fig. 2) During the same time period, the prevalence of pe keeping and smoking indoors decreased. The sam trend was seen for asymptomatic children. I asymptomatic children exposure to cigarette smoke i the home decreased from $57.2 \%$ in 1989 to $43.9 \%$ i 6997. Pet ownership decreased from $56.0 \%$ in $1993 \mathrm{t}$ $49.6 \%$ in 1997

\section{Discussio}

The results of the present study are consistent wit ather reports of a rising trend in asthma prevalence $\mathrm{i}$ the Netherlands and other countries worldwide ${ }^{3-8,12,1}$ The increase in recent wheezing and the large increas in the prevalence of chronic cough previousl described in Dutch childre ${ }^{5}$ dcould not be confirme by our results. In the present study the prevalence o racent wheezing decreased in 5-6 year-olds fro $22.1 \%$ in 1989 to $18.3 \% 1997$, whereas the prevalenc of chronic cough increased only slightly

Table 1. Sex and age distribution of the participating children in 1989, 199 and 199

\begin{tabular}{|c|c|c|c|c|c|c|}
\hline & \multicolumn{2}{|c|}{998} & \multicolumn{2}{|c|}{399} & \multicolumn{2}{|c|}{$\$ 997$} \\
\hline & $\mathbf{n}$ & $\%$ & $\mathbf{n}$ & $\%$ & $\mathbf{n}$ & $\%$ \\
\hline & \multicolumn{6}{|c|}{ A-7 year-old childre } \\
\hline 4 year & 64 & 60. & 72 & 6. & 3 & 1. \\
\hline 5-6 year & $\$ 22$ & 88. & 079 & $\theta 3$. & 086 & 88. \\
\hline 8 year & 7 & 0. & 8 & $\theta$. & 1 & 0.0 \\
\hline \multicolumn{7}{|c|}{ 8-12 year-old childre } \\
\hline 8-9 year & 657 & 87. & 848 & 69. & 760 & 89. \\
\hline 89 year & 81 & 22. & 6 & $\theta$. & 3 & 0. \\
\hline \multicolumn{7}{|l|}{ Sex } \\
\hline Mal & (1061 & 80. & 980 & 81. & 244 & 31. \\
\hline Eemal & 656 & 39. & 268 & 48. & 832 & 48. \\
\hline
\end{tabular}




\section{Driginal Researc}

Table 2. Prevalence of respiratory symptoms, physicians visits and school absence in the past 12 months and medication use in th past month by age group and year of stud

\begin{tabular}{|c|c|c|c|c|c|c|c|c|}
\hline \multirow{2}{*}{\multicolumn{2}{|c|}{998}} & \multicolumn{2}{|r|}{ 5-6 year-old } & \multirow[b]{2}{*}{$\ddot{\text { p} \text {-value* }}$} & \multirow[b]{2}{*}{998} & \multicolumn{3}{|c|}{ 8-9 year-old } \\
\hline & & 399 & $\$ 997$ & & & 399 & $199 *$ & p-valu * \\
\hline gVheezin & $22.1 \nmid 305$ & $20.6 \lcm{\lfloor 402}$ & 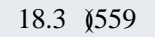 & 0.00 & $13.4 \curlyvee 240$ & $13.3 \gamma 203$ & $11.9 \nmid 198$ & $8.216 \mathrm{~N}$ \\
\hline $\begin{array}{l}\text { Shortness of breath wit } \\
\text { gheezin }\end{array}$ & $7.4 \hat{\Upsilon} 102$ & $8.1 \grave{\gamma} 159$ & $9.1 \nmid 281$ & ๑. $044<0.0$ & $5.7 \hat{\gamma} 103$ & $7.4 \curlyvee 113$ & $7.9 \hat{\gamma} 131$ & $0.013<0.0$ \\
\hline Shortness of breat & 4. $\ 102$ & $9.1 \curlyvee 177$ & $9.3 \curlyvee 283$ & $8.056 \mathrm{~N}$ & $6.5 \curlyvee 116$ & $7.9\lceil 121$ & 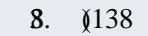 & $0.037<0.0$ \\
\hline Coughing with phlegm & $7.9 \lcm{\gamma} 109$ & $7.3 \times 142$ & $7.3 \Upsilon 221$ & $8.532 \mathrm{~N}$ & $3.9 \nvdash 70$ & 4. $\times 67$ & $3.8 \times 62$ & 8. $852 \mathrm{~N}$ \\
\hline Chronic cough & $4.0 \backslash 55$ & $4.5 \bigcirc 88$ & $4.5 \hat{\gamma} 137$ & $8.502 \mathrm{~N}$ & $2.1 \hat{\nvdash} 37$ & $2.0 \nmid 31$ & $2.7 \hat{\gamma} 45$ & 8.198 N \\
\hline \multicolumn{9}{|l|}{ General } \\
\hline Physicians visit & $75.9 \times 1049$ & $78.8 \gamma 1531$ & $75.3 \gamma 2300$ & $8.279 \mathrm{~N}$ & $58.1 \gamma 1043$ & $64.6 \times 983$ & $57.4 \gamma 937$ & $8.771 \mathrm{~N}$ \\
\hline Medication us & $30.0 \lcm{\imath} \quad 415$ & 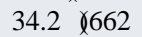 & $29.1 \nmid 891$ & $8.152 \mathrm{~N}$ & $19.6\lceil 351$ & $24.4 \hat{x} 368$ & $19.3 \grave{\nvdash} 318$ & $8.912 \mathrm{~N}$ \\
\hline School absenc & 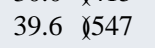 & $35.0 \lcm{685}$ & 28. $\quad 1868$ & $0.000<0.00$ & $22.2 \lcm{398}$ & $24.2 \times 369$ & 93. $\Upsilon 230$ & $0.000<0.00$ \\
\hline \multicolumn{9}{|l|}{ For respiratory complaints } \\
\hline Physicians visit & $22.7 \quad \nvdash 314$ & $23.6 \curlyvee 459$ & $21.8 \times 664$ & $8.340 \mathrm{~N}$ & 62. & $14.4 \times 219$ & 91. $\ 197$ & $8.594 \mathrm{~N}$ \\
\hline Medication us & $14.0 \quad \gamma 193$ & $14.9\lceil 288$ & $14.8 \gamma 453$ & $8.555 \mathrm{~N}$ & $9.4 \lcm{169}$ & $11.2 \gamma 169$ & $10.5 \nvdash 174$ & 8.268 N \\
\hline School absenc & 8. $\backslash 118$ & $13.4 \nmid 262$ & 9. $\times 293$ & $8.902 \mathrm{~N}$ & 8. 886 & 9. $\Varangle 120$ & $9 . \quad 64$ & 8. $288 \mathrm{~N}$ \\
\hline
\end{tabular}

The exact causes of the increasing asthma prevalenc æmain largely unexplained. In explaining this tim trend different factors should be considered, such a changes in indoor and outdoor environmental factors diagnostics and the possibility of an artefactua finding. Considering the spatial pattern of asthm prevalence, outdoor air pollution is probably not major factor ${ }^{2}$ for regions with a high level of ai pollution the lowest rates of asthma prevalence wer teported, whereas some regions with the lowes

Figure 2. Prevalence of physicians visits and school absence in the past year medication use in the past month, smoking and pet keeping indoors $i$ children with asthmatic symptoms and in children with coughing (*Pearsons $\chi^{2}$ test, $\leq \mathbf{0 . 0 1}$; ** Mantel-Haenszels $\chi^{2}$ pest, $\leq \mathbf{0 . 0 1}$ )

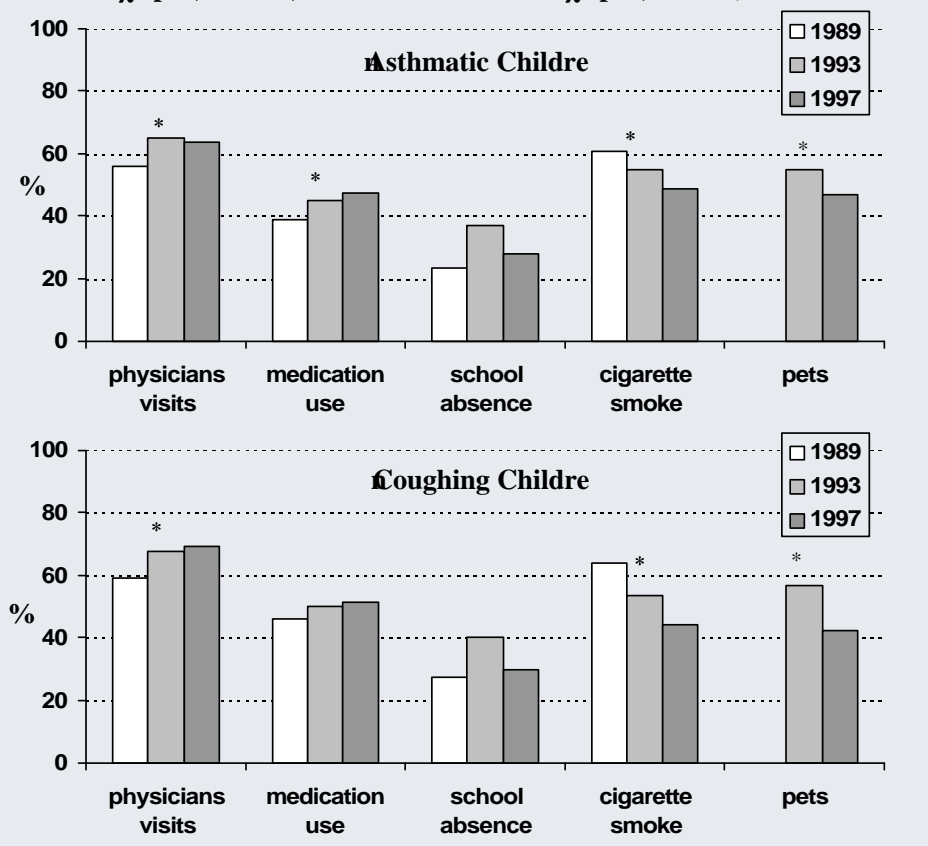

degrees of air pollution had high asthma prevalences ${ }^{2}$ The Westelijke Mijnstreek has an airport, a larg ehemical industry and heavy traffic which could hav bad some influence on the prevalence rates in th present study.

The association between indoor risk factors such a dnvironmental tobacco smoke, pet ownership an presence of dampness or moulds and respirator symptoms has been established in several studies ${ }^{64-1}$ However, the increased prevalence of wheezing foun in an English study could not be explained by chang in indoor factors ${ }^{1}$ Exposure to environmenta tobacco smoke or pet allergens was also unlikely $t$ Explain the increased prevalence of respirator symptoms found in the present study. Because th same trend in smoking behaviour and pet ownershi was also seen in asymptomatic children, informatio bias is unlikely to explain this finding

Increased frequency of asthma diagnoses has bee reported ${ }^{\text {S,1 }}$ Correspondingly, in the present stud physicians visits and medication use increased $\mathrm{i}$ symptomatic children. Better diagnostics of asthmati ohildren probably only partly explain the increase i asthma prevalence ${ }^{7}$ Better treatment may howeve œeduce asthma morbidity. In the present study $n$ questions on severity of asthma symptoms wer included

Another possible explanation may lie in an increase necognition and tendency to report symptoms as konsequence of rising publicity and professiona concern in recent years ${ }^{\mathbb{1}}$ The decreasing prevalenc gf wheezing and at the same time increasin drevalence of shortness of breath, might be explaine in terms of labelling differences between the stud sears. This is however unlikely, since the proportio 6f wheezy children additionally reporting shortness o breath, also increased from 1989 to 1997. Therefore 
the increase in shortness of breath with wheezing ca drobably be explained in terms of an increase prevalence of shortness of breath. Furthermore eonsidering the increased frequency of medication us it is likely that the severity of illness has increased. en the present study no objective measures wer included to ascertain whether the observed trend was true one. The results from the few studies that hav ased more clinical diagnostic methods support a tru increase in asthma prevalence ${ }^{\$ 3,1}$ ms was als eoncluded for the increasing asthma prevalence in th Netherlands 9

Because the survey was performed in the sam standardised way in all three study years the results ar Bighly comparable between the study years. In table we presented 22 tests of significance, with seve reaching statistical significance. We should however b aware that in view of the $95 \%$ confidence limits $\mathrm{w}$ assumed when performing the tests, we accepted th probability that five out of 100 confidence interval miss their true value. When performing 22 tests, one expected to be a false positive result (Type I error)

In conclusion, our findings are in line with earlie reports of a rising trend in asthma prevalence an ereatment. These changes however, can not b explained in terms of changed exposure to cigarett smoke or pets. We were unable to determine whethe mcreased treatment resulted in lesser morbidity $i$ symptomatic children

Khe Municipal Health Service Westelijke Mijnstree yill continue to monitor the prevalence of respirator symptoms in their region, and in the fourth survey (i ฉ001) the questionnaire was extended with items o severity of symptoms.

\section{scknowledgemen}

The authors wish to thank the members of the Yout Eealth Care Section of the Municipal Health Servic yWestelijke Mijnstreek for their cooperation in the stud and Cindy Gielkens for reading the manuscript

\section{Reference}

,1. Spee-van der Wekke J, Meulmeester JF, Radder JJ tVerloove-Vanhorick SP. School absence and treatmen in school children with respiratory symptoms in th gletherlands: data from the Child Health Monitorin System. J Epidemiol Community Health 1998 \$ $\div 359$ 63

ฉ. ISAAC Steering Committee. Worldwide variation i prevalence of symptoms of asthma, allergi rhinoconjunctivitis, and atopic eczema: ISAAC. Lance 1998 195 : 1225-32

3. European Community Respiratory Health Survey ,Variations in the prevalence of respiratory symptoms aelf-reported asthma attacks, and use of asthm medication in the European Community Respirator Health Survey (ECRHS). Eur Respir J ;1996 9:687-95
4. von Mutius E, Martinez FD, Fritzsch C, et al Prevalence of asthma and atopy in two areas of Wes and East Germany. Am J Respir Crit Care Me ;994 94 :358-64

.5. van der Wal MF, Uitenbroek DG, Verhoeff AP tToegenomen percentage basisschoolkinderen me astmatische klachten in Nederland, 1984/'85-1994/'95 een literatuuronderzoek. Wed Tijdschr Geneesk $200044: 1780-5$

6. Weiss KB, Gergen PJ, Wagener DK. Breathin better or wheezing worse? The changing epidemiolog of asthma morbidity and mortality. Annu Rev Pub Healt $1993 \mathbf{4}: 491-513$

7. Nystad W, Magnus P, Gulsvik A, et al Ghangin prevalence of asthma in school children: evidence fo diagnostic changes in asthma in two surveys $13 \mathrm{yr}$ apart. Eur Respir ;1997 0 :1046-51

8. Omran M, Russell G. Continuing increase i nespiratory symptoms and atopy in Aberdee schoolchildren. $\mathbb{B r}$ Med $; 996 \mathbf{3 1}: 34$ 9. Tirimanna PRS, van Schayck CP, den Otter JJ, et al Rrevalence of asthma and COPD in general practice $\mathrm{i}$ 1992: Has it changed since 1977? Br J Gen Prac ;1996 6 :277-81

d0. Werkgroep CARA bij jeugdigen. De Regio's studi geel I en deel II. Afdelingen jeugdgezondheidszor DGD voor Flevoland, DGD Noordoost Friesland, GG Midden Holland en Vakgroep Sociale Geneeskunde e Epidemiologie Rijksuniversiteit Groningen, 1988 n1. Verkerk PH, Rijcken B. Evaluatie van ee eragenlijst naar respiratoire symptomen en $\mathrm{d}$ maatschappelijke gevolgen hiervan in een ope populatie T Soc Gezondheids 19886 :102-5 112. Anderson HR, Butland BK, Strachan DP. Trends i prevalence and severity of childhood asthma. $\mathbb{B r}$ Med ;1994 80 :1600-4

13. Downs SH, Marks GB, Sporik R, et al Continue increase in the prevalence of asthma and atopy. Harc Dis Chil 200184 20-3

d4. Cook DG, Strachan DP. Parental smoking an prevalence of respiratory symptoms and asthma i school age children Thorax;1997 $\mathbf{8}: 1081-94$ 15. Burr ML, Anderson HR, Austin JB, et al Respiratory symptoms and home environment $\mathrm{i}$ children: a national survey. Thora ;999:27-32 16. Dijkstra L, Houthuijs D, Brunekreef B, et al Respiratory health effects of the indoor environment $i$ a population of Dutch children. Am Rev Respir Di ;990 24 :1172-8

d7. Butland BK, Strachan DP, Anderson HR. Th home environment and asthma symptoms in childhood swo population based case-control studies 13 year apart. Thorax;1997 $\mathbf{8}: 618-24$

18. Peat JK, Van Den Berg RH, Green WF, et al Changing prevalence of asthma in Australian children Br Med J 199480 : 1591-6 